\title{
Editorial
}

\section{Human problems in the automated factory?}

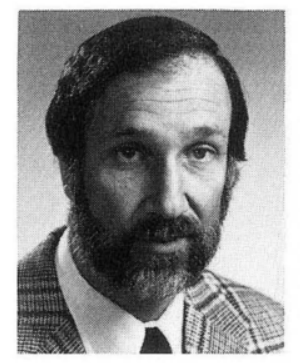

Donald Gerwin. Currently, I'm a professor at the School of Business Administration at the University of Wisconsin-Milwaukee. I received by $\mathrm{Ph} . \mathrm{D}$. in Industrial Administration from Carnegie-Mellon University where my interest in human problem solving developed. I've also visited at the University of Wisconsin in Madison, the International Institute of Management in Berlin and ESSEC in Cergy, France.

Trying to understand problem solving led me to research in administrative decision making and scientific inference. I've published a book "Budgeting Public Funds" and articles in Management Science, Administrative Science Quarterly and other journals on the former topic; and papers in Behavioral Science and elsewhe:e on the latter topic. My interest in the design of problem solving systems led me to work on organizational design, especially where technological considerations are important. I've published on this topic in Management Science and various management journals, and am completing a handbook chapter on the relationships between structure and technology. At the moment I'm involved in a field study of the organizational impacts of advanced manufacturing systems. We are trying to trace the processes by which new technology interacts with structure, policy making, and other variables.

In addition to being on the editorial board of Human Systems Management, my professional activities include being an associate editor for Management Science, and a consultant to the Division of Applied Research of NSF.

North-Holland Publishing Company

Human Systems Management 3 (1982) 159-161
Scarcely ten years ago, the major problems of U.S. manufacturing appeared to be solved, and interest was turning to our burgeoning service sector. But since then the cycle has swung back with a viciousness that has left the nation reeling. The plight of our auto and steel industries is just one example of the pressing need to make fundamental changes in the management of manufacturing and in manufacturings' relationship to the rest of the firm. Who would have believed a decade ago that such issues as federal aid to develop new technologies, the need for more manufacturing people in top management, and the effect of a short run profit orientation on capital investment would be seriously debated in the early eighties.

Once again there is a strong belief that problems which have important organizational, strategic, and social aspects can be solved by revolutionary technological developments. And the technology is here in the form of computerized operation and control of manufacturing equipment for discrete parts. Computer aided manufacturing is perhaps the most significant advance in production technology since the assembly line. In fact, it is likely to do away with the assembly line as we know it.

Computer aided manufacturing started around 1969 with the introduction of computer numerical control $(\mathrm{CNC})$ machine tools. A stored-program mini or microcomputer controls cutting operations so that modifications to accommodate product design changes or new parts can be made by merely changing the program. The computer can also be used for machine monitoring, scheduling, and the reporting of performance data. The next advance was the computer integrated manufacturing system (CIMS). A CIMS consists of a battery of $\mathrm{CNC}$ machine tools linked to a central computer for control and reporting purposes, in combination with automated material handling between the machines [1]. 
Production engineers have predicted that by the year 2000 , less than nineteen years away, the computer integrated automated factory will be a reality [2]. Each activity in the flow of work (processing, assembly, inspection, transport, and storage) will be automated and integrated into a single system under computer control. Perhaps a dozen people will supervise, program and operate the computer, maintain and repair equipment, and perform engineering analysis and design. No one, according to this scenario, will be directly involved in manufacturing the product.

Clearly the trend is toward more sophisticated, large scale, centralized, and capital intensive production equipment. Manufacturing provides a sobering counterexample to Zeleny's optimistic thesis, expressed in an earlier HSM Editorial [3], that perhaps we have been moving all along toward decentralized, small scale, 'demassified', home-centered technology. Are we then going to repeat the mistakes of the past? All the indications are that this is already happening. The march toward the integrated factory is to the tune of assumptions that have already proved illusory in other technological arenas.

Let's examine two of these assumptions. The first might be termed the controllability assumption. Manufacturing operations need to be efficient. The way to achieve efficiency is through predictability and control. The behavior of humans is a major source of uncertainty which can be removed by the substitution of capital for labor. Hence, the more automated a factory becomes, the more controllable it will be.

This view completely avoids the fact that humans are a source of innovative ideas for improving the production process. Once more, humans represent highly flexible resources which can be used to deal with the rigidities of computerized automation. These rigidities often produce unanticipated problems which are most effectively handled by adding more human input than was originally intended.

For example, one rigidity of computer integrated manufacturing systems is that sophisticated quality checks are most readily made at the end of the machining process where a natural pause exists in the flow of work. By the time a damaged part is discovered, other parts or the machines can be affected. One company with which I am familiar solved this problem by hiring more inspectors to speed up checking at the end of the process. A second company programmed the central computer to shut off machines at random times so that the parts being processed could be inspected by the machine operators. Hiring additional operators was necessary.

A second example concerns research on production scheduling for CIMS at a leading European institute. Originally, the objective had been to fully automate the entire procedure, but the resulting model was too rigid to deal with unanticipated changes due to machine breakdowns and work piece faults. Now the goal is to design an interactive system.

To recapitulate, the assumption is that problems with people can be avoided by automation. The reality is that problems with automation need to be overcome using people.

The second assumption is the integration assumption. Increases in manufacturing productivity come automatically from the introduction of new technology. The more sophisticated the equipment and the faster its implementation, the higher will be productivity. Human and organizational factors need not be considered, or can be dealt with after the equipment is functioning. On the surface this is a compelling argument since as we progress toward the automated factory, shouldn't human and organizational considerations become less significant?

On the contrary. Computerized automation must be integrated with human activity in almost every corner of the manufacturing firm if it is to realize its potential. It requires a support system consisting of people's skills, attitudes and motivations; systems and procedures; and company-wide policies in order to operate effectively. Where there is a mismatch between technology and support system, effectiveness will suffer. In particular, where the new equipment requires a more sophisticated support system than exists there are likely to be unanticipated problems.

The best evidence of widespread belief in the integration assumption is the surprisingly low utilization rates of computer integrated manufacturing systems in many firms. In one company I know of, the CIMS has a utilization rate about equal to that of the stand-alone equipment in the shop. Many of the reasons for these low rates stem from inadequate support systems. Not enough concern is devoted to motivating direct workers who tend the 
machines or load and unload parts. Yet these people exercise considerable power to affect production through the pace at which they work. There are not enough skilled maintenance people to handle complex electronics problems, and these individuals are reluctant to work second and third shifts. Consequently, machine reliability is a constant headache. New accounting systems are needed to control the costs of computerized manufacturing but production managers have difficulty in understanding and applying them.

Finally, many companies do not recognize the impact that computerized automation has on their overall strategy, and therefore do not take full advantage of the equipment. Consider an American firm which purchased a CIMS to manufacture a new part without accepting its potential for machining several other parts. Subsequently, demand for the new part slackened, which necessitated putting new ones on the system. Management, unprepared for this turn of events, had to scramble to find new tooling, fixtures, and parts programs while idle time mounted.

To summarize, the assumption is that sophisticated technology will lead to high productivity irrespective of the state of the firm's support system. The reality is that relatively unsophisticated technology integrated with a compatible support system may have higher productivity.

For these reasons I am convinced that the productive automated factory will take much longer to achieve than is currently believed. Further, if we do not come to grips with the human and organizational dilemmas posed, we may never see automated factories that function effectively. Here are some suggestions:

(1) Vendors must be aware that human and organizational issues are at least as important as engineering design problems. Perhaps this will occur when it becomes clearer that the rate of diffusion of computerized equipment is being hampered by such non-technical considerations. Potential users have a role to play here by emphasizing to vendors the need for integrating new equipment within the organization.

(2) User task forces appointed to investigate alternative equipment designs should consist of representatives of potentially affected areas. Staff and service people, plant management, and workers need to be included. A task force consisting primarily of manufacturing engineers is not likely to consider the impacts of a particular design on these other groups.

(3) Companies might consider appointing a 'process' manager, analogous to a product manager, who would be responsible for integrating the diverse interests affected by a particular system. $\mathrm{He}$ or she would function from the moment the need for the system is recognized until it is phased out.

(4) Firms considering the purchase of computerized equipment must pay attention to whether their support systems are adequate for interacting with it. Those which want to adopt sophisticated equipment without having the necessary experience are just asking for trouble. What is needed is a comprehensive human and organizational development plan which is instituted before the equipment arrives.

(5) The most automated equipment available may not always provide the right answer, especially for companies with inadequate support systems. Less sophisticated alternatives which put more stress on interaction with human resources should not be overlooked.

Is it possible to avoid our past mistakes? Only if we realize that the development of computer aided manufacturing must not be guided solely by technical considerations.

Donald GERWIN

\section{References}

[1] D. Gerwin and T. Leung, The organizational impacts of flexible manufacturing systems: some initial findings, $\mathrm{Hu}$ man Systems Management 1 (1980) 237-246.

[2] M.E. Merchant, The inexorable push for automated production, Production Engineering (1977) 44-49.

[3] M. Zeleny, Editorial: Multiple scenarios of 'reindustrialization', Human Systems Management 1 (1980) 281-282. 